Sveučilišni odjel za stručne studije, Sveučilište u Splitu, Split, Republika Hrvatska sborovac@oss.unist.hr

\title{
POVEZANOST ORGANIZACIJSKE KULTURE KAO KLJUČNOG ČIMBENIKA IZGRADNJE UČEĆEG PODUZEĆA I PERFORMANSI PODUZEĆA
}

Primljen: 27. lipnja 2018.

Prihvaćen: 28. kolovoz 2018.

Pregledni rad

\section{Sažetak}

Očigledno je kako danas više nego postoji potreba da poduzeća kontinuirano rade na svojoj izvrsnosti putem procesa prilagodbe. U postizanju tog cilja nužno je pokrenuti sve resurse znanja u poduzeću. Trajne prednosti u odnosu na konkurenciju postižu se isključivo pomoću znanja. Ova tvrdnja osobito vrijedi u slučajevima kada se znanje nekog poduzeća teško može ili uopće može kopirati. To osobito vrijedi za organizacijsku kulturu koja potiče suradnju i razmjenu znanja. Sposobnost učenja nekog poduzeća i njegova sposobnost upotrebe relevatnog znanja u svom poslovanju, odnosno da se naučeno ne zaboravi, ima veliko značenje u doba poduzeća temeljenih na znanju. Znanje i učenje tako postaju rijetkima $i$ vrijednima izvorima konkurentske prednosti pa je, između ostalog, upravo iz navedenih razloga, postalo iznimno teško u današnje vrijeme pronaći menadžera koji barem deklarativno ne pridaje važnost organizacijskoj klimi i izgradnji učećeg poduzeća. Kako bi se neko poduzeće uspješno transformiralo u učeće poduzeće ono treba, kao prvi korak u tom procesu, identificirati nivo kulture kojoj pripada nakon čega bi trebalo prepoznati slabe točke koje je potrebno mijenjati. Transformacija poduzeća čija je unutarnja kultura ,negativna“ ili kako je pojedini autori još i nazivaju ,patološka“ ili ,birokratska“ trebala bi se promijeniti u poduzeće s pozitivnom-generativnom unutarnjom organizacijskom kulturom. Sve navedeno u konačnici bi trebalo imati pozitivan utjecaj na organizacijske performanse.

Ključne riječi: organizacijska kultura, učeće poduzeće, prilagodba poduzeća, performanse

JEL: M14 


\section{UVOD}

Organizacijska kultura spada među važnije čimbenike uspješnosti poslovanja poduzeća. Naziva se još i kulturom poduzeća ili korporacijskom kulturom i predstavlja, za mnoge autore, jedan od najobuhvatnijih koncepata organizacijske teorije. Pojmu organizacijske kulture se u posljednje vrijeme pridaje sve više pažnje iako je sam pojam već desetljećima prisutan u stručnoj literaturi organizacije i menadžmenta. Pod organizacijskom kulturom se podrazumijeva unutarnje ozračje prisutno u poduzeću a kojem se novopridošli članovi prilagođavaju. Za nju se može reći kako predstavlja osobnost poduzeća. Nju se nipošto ne može promatrati kao jednodimenzionalni kocept iz razloga što je ona rezultat dugotrajnog procesa u kojem se stavovi, vjerovanja i ponašanja zaposlenih oblikuju tijekom dužeg vremenskog perioda.. U ovom radu teorijski se dokazuje važnost organizacijske kulture kao ključnog čimbenika izgradnje učećeg poduzeća koji predstavlja adekvatnu platformu za ostvarivanje uspješne prilagodbe poduzeća njegovoj okolini što se u konačnici odražava na performanse poduzeća. Organizacijska kultura time postaje najvažniji čimbenik uspješne prilagodbe poduzeća promjenjivoj i zahtjevnoj okolini.

\section{POJAM I DEFINICIJA ORGANIZACIJSKE KULTURE}

Prije nego se pokuša objasniti pojam organizacijske kulture, potrebno je definirati pojam kulture kojeg ona označava u jednom širem smislu. Kultura u najširem smislu riječi kako ju definira Žugaj (2005) „označava preradbu i usavršavanje nečega, neke građe, nekog materijala za određenu svrhu“. U užem smislu riječi kultura, prema objašnjenju istog autora, ,predstavlja ostvarivanje humanih vrijednosti u čovjeku i njegovim djelima“. Za razliku od djela koja obuhvaćaju sredstva za proizvodnju i ostale materijalne tvorevine, što čini materijalnu kulturu, duhovna kultura nosi svoje vrijednosti same u sebi. Duhovna kultura je ukupnost rezultata znanosti, umjetnosti, filozofije, moralnih čina i običaja.

Razlog iz kojeg je bilo potrebno definirati opći pojam kulture jest taj što ona predstavlja temelj za razumijevanje organizacijske kulture, iz razloga što je organizacijska kultura u pravilu sastavni element opće kulture i vrijednosnog sustava društva u cjelini. Nažalost, ne postoji jedna precizna i potpuna definicija organizacijske kulture. Konzultirajući dostupnu literaturu može se uočiti priličan broj autora koji istražuju navedenu tematiku i isto tako jednako velik broj različitih definicija organizacijske kulture.

Organizacijska kultura obično je definirana načinom na koji zaposlenici u poduzeću razmišljaju, što za posljedicu ima izravan utjecaj na način na koji se ponašaju. Tako primjerice, uviđajući da se kultura očituje u pogledu ponašanja i 
usvojenih vrijednosti, Schein (2010) ukazuje na činjenicu da suština kulture leži u skupu "temeljnih pretpostavki". Slično tome, Deshpande i Webster (1989) definiraju organizacijsku kulturu kao "skup zajedničkih pretpostavki i razumijevanja o funkcioniranju poduzeća."

Teorijska postavka svih razmišljanjima o organizacijskoj kulturi počiva na uvjerenju kako je ona kompleksan sustav normi i vrijednosti koje se oblikuju tijekom vremena (Schein, 1996). Ona se općenito smatra, kako je pojedini autori (Prosser, J., 1999) nazivaju, „socijalnim ljepilom“ koje drži na okupu zaposlenike u poduzeću i oslikava usvojene vrijednosti, društvene ideale i uvjerenja koja oni dijele. Kultura nekog poduzeća, dakle, preko svojih vrijednosti i usvojenih uvjerenja, vrši presudan utjecaj na način kako zaposlenici u tom poduzeću opažaju događaje (Denison i Mishra, 1995) i kako se ponašaju (Schein, 1985; Barney, 1986). Organizacijska kultura obuhvaća vrijednosti i ponašanja koja "pridonose jedinstvenom društvenom i psihološkom okruženju poduzeća. “

Poznato je kako je organizacijska kultura važna za uspjeh projekata koji uključuju provođenje promjena u poduzeću. Na primjer, Martinsons i Chong (1999) su istražujući utjecaj primjene sofisticirane tehnologije na performanse poslovanja došli do rezultata kako se nije postigao očekivani rast performansi i to iz potpuno netehničkih razloga. Naime ključan faktor koji je „opstruirao“ očekivani rast performansi bio je ljudski faktor. Autori su tako zaključili kako "čak $i$ dobra tehnologija može biti sabotirana ukoliko se vjeruje da ometa etabliranu društvenu mrežu." Njihovo otkriće podržao je Cooper (1994), koji je u svojim istraživanjima došao do saznanja kako će se, u slučaju kada informacijska tehnologija dođe u konflikt s organizacijskom kulturom, implementaciji te iste tehnologije oduprijeti na jedan od dva načina; ili će sustav biti odbijen ili će se izmijeniti tako da odgovara postojećoj kulturi. Prema Needleu (2004), organizacijska kultura predstavlja kolektivne vrijednosti, uvjerenja i principe zaposlenika u nekom poduzeću te se vezuje uz i nastaje kao proizvod različitih čimbenika kao što su; prošlost poduzeća, proizvod, tržište, tehnologija i strategija, zaposlenici, stil upravljanja i nacionalna kultura. Kultura uključuje viziju, vrijednosti, norme, sustave, simbole, jezik, pretpostavke, uvjerenja i navike koji su prihvaćeni u nekom poduzeću. Ravasi i Schultz (2006) su u svojim longitudalnim istraživanjaima o utjecaju promjena u okolini na organizacijsku kulturu došli do zaključka kako se organizacijsku kulturu može opisati kao skup zajedničkih pretpostavki koje upravljaju onim što se događa u poduzeću definiranjem primjerenog ponašanja u različitim situacijama. Ona je ujedno i obrazac ustaljenih kolektivnih ponašanja i pretpostavki s kojima se suočavaju novi zaposlenici u poduzeću (putem percipiranja), pa čak, razmišljanja i osjećanja. 
Dakle, organizacijska kultura utječe na način na koji se zaposlenici i grupe odnose jedni prema drugima, s kupcima, klijentima i ostalim akterima u svom poslovanju. Osim toga, organizacijska kultura utječe i na stupanj identifikacije zaposlenika sa samim poduzećem (Schrodt, 2002). Velik broj autora dijeli mišljenje kako se organizacijskom kulturom može svjesno manipulirati (Schein, 1985; Block, 2003) a kao ključan čimbenik tog procesa ističe vodstvo (Senge, 1990; Vera i Crossan, 2004; Waldman i sur., 2001). Dakle, glavni zadatak vrhovnog menadžmenta postaje stvaranje takve organizacijske klime koja će podržavati njihove napore za provođenjem promjena i kontinuirano raditi na izgradnji takve organizacijske kulture koja će poticati i stimulirati promjene.

\subsection{Obiljě̌ja organizacijske kulture}

Za organizacijsku kulturu se može reći kako je promjenjiva kategorija jer je podložna promjenama koje dolaze iz okoline poduzeća. U tablici 1. Prikazana su obilježja organizacijske kulture prema istraživanju Daniela R. Denisona i Aneila K. Mishrae (1995).

Tablica 1. Obilježja organizacijske kulture

\begin{tabular}{|c|c|}
\hline \multicolumn{2}{|c|}{ Uključenost zaposlenika } \\
\hline Opunomoćivanje & 1.Većina zaposlenika znatno je uključena u svoj rad. \\
\hline \multirow{7}{*}{ Timska orijentacija } & $\begin{array}{l}\text { 2.Odluke se obično donose na razini na kojoj su dostupne naj- } \\
\text { kvalitetnije informacije. }\end{array}$ \\
\hline & $\begin{array}{l}\text { 3.Informacije se prenose cijelim poduzećem tako da svatko } \\
\text { može dobiti informaciju gdje i kada mu je potrebna. }\end{array}$ \\
\hline & 4.Svatko vjeruje da može dati pozitivan doprinos. \\
\hline & $\begin{array}{l}\text { 5.Poslovno planiranje uključuje, do određenog stupnja, sva- } \\
\text { kog zaposlenog u poduzeću. }\end{array}$ \\
\hline & 6.Aktivno se ohrabruje suradnja različitih dijelova poduzeća. \\
\hline & 7.Svi pojedinci rade kao da su dio tima. \\
\hline & $\begin{array}{l}\text { 8.Rad je organiziran tako da svaki pojedinac može vidjeti vezu } \\
\text { između svog posla i ciljeva poduzeća. }\end{array}$ \\
\hline \multirow{3}{*}{$\begin{array}{l}\text { Razvoj sposobnosti } \\
\text { (vještina) }\end{array}$} & $\begin{array}{l}\text { 9. Ovlasti su delegirane tako da zaposlenici mogu samostalno } \\
\text { djelovati. }\end{array}$ \\
\hline & $\begin{array}{l}\text { 10.Kontinuirano se ulaže u unapređivanje znanja i vještina za- } \\
\text { poslenika. }\end{array}$ \\
\hline & $\begin{array}{l}\text { 11. Sposobnosti (karakteristike) ljudskih potencijala smatraju } \\
\text { se važnim izvorom komparativnih prednosti. }\end{array}$ \\
\hline
\end{tabular}




\begin{tabular}{|c|c|}
\hline Temeljne vrijednosti & $\begin{array}{l}\text { 12.Vođe i menadžeri „prakticiraju ono što propovijedaju“. } \\
\text { 13.Razvijen je karakterističan stil menadžmenta. } \\
\text { 14.Postoji jasan i konzistentan sustav vrijednosti koji upravlja } \\
\text { načinom poslovanja. } \\
\text { 15.Postoji i etički kodeks koji usmjerava ponašanje zaposleni- } \\
\text { ka i pomaže da razlikuju dobro od lošeg. }\end{array}$ \\
\hline Suglasnost & $\begin{array}{l}\text { 16.Oblikovana je „snažna“ kultura. } \\
\text { 17.Lako se postiže konsenzus čak i kod teških problema. }\end{array}$ \\
\hline $\begin{array}{l}\text { Koordinacija i } \\
\text { integracija }\end{array}$ & $\begin{array}{l}\text { 18.Ljudi iz različitih dijelova poduzeća dijele zajedničke po- } \\
\text { glede prema budućnosti. } \\
\text { 19.Lako se koordiniraju projekti koji uključuju različite dije- } \\
\text { love poduzeća. } \\
\text { 20.Ciljevi različitih razina u poduzeću dobro su usklađeni. }\end{array}$ \\
\hline \multicolumn{2}{|l|}{ Prilagodba } \\
\hline Poticanje promjena & $\begin{array}{l}\text { 21. Način na koji se poslovi obavljaju fleksibilan je i lako se } \\
\text { mijenja. } \\
\text { 22.Poduzeće se dobro prilagođava konkurenciji i drugim pro- } \\
\text { mjenama poslovne okoline. } \\
\text { 23. Novi i poboljšani načini poslovanja kontinuirano se usvaja- } \\
\text { ju uz suradnju svih dijelova poduzeća. }\end{array}$ \\
\hline $\begin{array}{l}\text { Usmjerenost prema } \\
\text { potrošačima }\end{array}$ & $\begin{array}{l}\text { 24. Mišljenje i preporuke potrošača često vode promjenama. } \\
\text { 25. Svi članovi veoma su dobro upoznati sa željama i potreba- } \\
\text { ma potrošača. } \\
\text { 26. U poduzeću se potiće direktan kontakt zaposlenih sa po- } \\
\text { trošačima }\end{array}$ \\
\hline $\begin{array}{l}\text { Organizacijsko } \\
\text { učenje }\end{array}$ & $\begin{array}{l}\text { 27.Inovativnost i preuzimanje rizika ohrabruju se i nagrađuju. } \\
\text { 28.Učenje je važan element svakodnevnog posla. }\end{array}$ \\
\hline \multicolumn{2}{|l|}{ Misija } \\
\hline $\begin{array}{l}\text { Strateško usmjerenje } \\
\text { Ciljevi }\end{array}$ & $\begin{array}{l}\text { 29. Postoji jasna misija koja daje smisao i pravac našem radu. } \\
\text { 30.Oblikovana je jedna strategija za budućnost } \\
\text { 31.Vođe postavljaju ambiciozne, ali realistične ciljeve. } \\
\text { 32.Zaposlenici razumiju što se mora učiniti za dugoročan } \\
\text { uspjeh }\end{array}$ \\
\hline Vizija & $\begin{array}{l}\text { 33.Postoji jasna vizija o poduzeću i u budućnosti. } \\
\text { 34.Vizija poduzeća stvara zadovoljstvo i motivaciju zaposle- } \\
\text { nika }\end{array}$ \\
\hline
\end{tabular}

Izvor: Žugaj, M., Bojanić-Glavica, B. (2004) Teorijske odrednice organizacijske kulture Varaždin: TIVA. 
Schein (2004) koji se bavio istraživanjem utjecaja vodstva na izgradnju organizacijske kulture tvrdi kako upravo vrhovni menadžeri imaju presudan utjecaj na razvoj i održavanje organizacijske kulture. On menadžerima savjetuje izgrađivati i jačati one vrijednosti koje su od presudne važnosti za ostvarivanje organizacijske strategije, poslovnih ciljeva i stalne uspješnosti kako bi mogli upravljati organizacijskom kulturom. Upravljanje kulturom time postaje jedinstvena i suštinska funkcija vodstva.

\section{ULOGA ORGANIZACIJSKE KULTURE U IZGRADNJI UČEĆEG PODUZEĆA}

Organizacijska kultura svojim vrijednostima, običajima, uvjerenjima i normama oblikuje stavove i ponašanja zaposlenika u poduzeću te na taj način pomaže pripremiti „plodno tlo“ za provođenje promjena, a time i na njihovu uspješnu provedbu. Do ovog su zaključka došli Ćuze i Načinović (2015) pručavajući ulogu organizacijske kulture u provedbi promjena u poduzeću. Kako prihvaćanje provedenih promjena potaknutih od strane vrhovnog menadžmenta uvelike ovisi o stavu zaposlenih prema promjenama, iznimno je važno utjecati na izgradnju pozitivnog stava zaposlenika naspram promjena. Autori Kavanagh i Ashkanasy (2006) su istražujući utjecaj koji imaju vodstvo i strategije upravljanja promjenama na organizacijsku kulturu i individualno prihvaćanje promjena tijekom kriznih situacija došli do zaključka kako je za uspješnu izgradnju prilagodljive kulture potrebno zadovoljiti dvije pretpostavke (Whiteley, Price i Palmer, 2013):

- prva pretpostavka je da menadžeri i zaposlenici međusobno razmjenjuju mišljenja i stavove, a

- druga pretpostavka je da organizacijska kultura treba omogućiti da obje skupine mogu učiti jedna od druge.

Daft (2004) u svom djelu Teorija i dizajn organizacije (engl. Organization Theory and Design) ističe kako prilagodljivu organizacijsku kulturu karakterizira strateško fokusiranje na vanjsku okolinu putem fleksibilnosti i promjena u poduzeću s ciljem odgovora poduzeća na promijenjene zahtjeve tržišta. Prilagodljiva organizacijska kultura anticipira i mijenja se kao odgovor na promjene u okolini. Pa tako Belak i Ušljebrka (2014) u svom radu Organizacijska kultura kao čimbenik uspješne provedbe organizacijske promjene ističu kako ona najviše pridonosi iniciranju i implementiranju promjena u poduzeću jer podrazumijeva izuzetnu fleksibilnost i spremnost članova da pokrenu poduzeće iz jednog stanja u drugo, ovisno o promjenama u okolini.

Temeljne vrijednosti prilagodljive kulture vezuju se uz sklonost prema promjenama, preuzimanju rizika, međusobnoj podršci zaposlenika, inovativnosti, 
kreativnosti i entuzijazmu. Može se primjetiti kako su navedene vrijednosti potpuno identične onima koje se nalaze i kod učećeg poduzeća. Prilagodljiva kultura tako ima eksterni fokus i tendenciju konstantno težiti fleksibilnosti. Poduzeće s izgrađenom prilagodljivom kulturom cijeni svoje zaposlenike i potiču procese koji pridonose uvođenju i provedbi promjena. Zaposlenici u takvom poduzeću uživaju potpunu slobodu u donošenju odluka, predlaganju i iznošenju novih ideja dok ih se istovremeno potiče na samoinicijativno djelovanje. U već spomenutom radu Uloga organizacijske kulture u provedbi organizacijskih promjena autorica Ćuze i Načinović (2015) su došle do zaključka kako organizacijska kultura aktivno potiče poduzetničke vrijednosti, norme i vjerovanja koja podupiru sposobnost poduzeća da uoči, interpretira i prevede znakove iz okoline kao nov način djelovanja i time promiče filozofiju o mogućnosti uspješnog nadvladavanja poteškoća u poslovanju iskorištavanjem prilika iz okoline.

Upravo se vrhovni menadžment poduzeća smatra odgovornim za izgradnju i promicanje adaptivnih vrijednosti koje se zatim prenose na sve ostale rukovodeće nivoe u poduzeću. Belak i Ušljebrka (2014) u početnoj fazi izgradnje organizacijske kulture ograničavaju ulogu vrhovnog menadžmenta na promicanje filozofije prilagodljive kulture koja će se potom uskladiti sa strategijom i ciljevima poduzeća. Osim ove uloge, vrhovni menadžment ima važan zadatak očuvanja organizacijske kulture koja potiče izvrsnost, adaptivne vrijednosti i fleksibilan stav prema svim ostalim vrijednostima. Ove autorice su u svom istraživanju o utjecaju organizacijske kulture na uspješnost provedbe organizacijske promjene došli do zaključka kako menadžer, ukoliko želi pridobiti zaposlene u poduzeću i steći njihovu naklonost u provođenju promjena i njihov pozitivan stav, treba oblikovati takav sustav vrijednosti u poduzeću i takav stil vodstva koji će poticati eksterni fokus, fleksibilnost, visoku društvenost, visoku solidarnost, psihološku sigurnost i povjerenje. Vrhovni menadžer je onaj koji bi trebao biti promicatelj prilagodljive kulture u svakodnevnim aktivnostima, komunikaciji i odnosu oprema zaposlenima i suradnicima te se ponašati u skladu s vrijednostima koje takva kultura promiče.

Poduzeće koje želi uspješno odgovoriti na zahtjeve okoline i održati konkurentsku prednost na tržištu, treba fleksibilnost postaviti kao svoj primarni cilj. Ključne odlike uspješnog poduzeća time postaju; prilagodljivost, sposobnost brzog strateškog reagiranja i izgradnja unutarnjeg sustava koji će omogućiti fleksibilnost s ciljem što bržeg odgovora na nepredvidljive promjene okoline. Promjene koje se događaju u okolini su posljednjih desetljeća sve turbulentnije te je opstanak na tržištu svakog poduzeća koje im se ne prilagodi na vrijeme doveden u pitanje. Samo prilagodljiva organizacijska kultura koja spremno prihvaća promjene, konstantno se prilagođavajući novim zahtjevima iz okoline može stvoriti preduvjete za rast i razvoj poduzeća i ostvarenje uspješnih performansi. 


\subsection{Povezanost organizacijske kulture i performansi poduzeća}

Belak i Ušljebrka (2014) tvrde kako ima već dugi niz godina kako je teoretski dokazano kako je organizacijska kultura ključan čimbenik uspješne provedbe promjena u poduzeću. Arie de Geus (2011) objašnjava u svom članku, engl. The Living Company, poduzeća koja su opstala dulje od jednog stoljeća poprimaju određene zajedničke značajke, upravo one koje su im omogućile da se prilagode važnijim, čak i radikalnim, promjenama u političkoj, društvenoj i ekonomskoj okolini. Jedna od tih karakteristika jest sposobnost stvaranja zajednice menadžera i zaposlenika koji su predani poduzeću kao dugoročnom pothvatu. Model kojeg su u svom radu Organizational culture and leadership style: key factors in the organizational adaptation process predložile Vrdoljak Raguž, I. i Borovac Zekan, S. (2017) sugerira kako se performanse poslovanja mogu poboljšati ukoliko zaposlenici rade u poduzeću čija unutarnja klima potiče pozitivnu energiju i stimulativnu radnu atmosferu te pojedincima pruža osjećaj zajedništva i pripadnost timu. Ova istraživanja jasno i sustavno pokazuju da i izvrstan radni učinak i dugoročni opstanak u velikoj mjeri ovise o naravi i dubini predanosti zaposlenika poduzeću. Ne možemo reći da ova činjenica predstavlja novinu. Ono što bi ipak mogla biti novost, barem nekima, jest dokaz koji govori tome u prilog. Danas više nego ikad, poduzeće ima potrebu za predanim zaposlenicima kako bi se uspješno natjecala na međunarodnom tržištu. Prema tome, treba pridati više pažnje utjecaju odluka uprave na predanost zaposlenika. Baš kao što se strategija bavi gospodarskim posljedicama odluka uprave, tako i i autori Pablo Cardona i Carlos Rey (2008) u svojoj knjizi „Upravljanje pomoću misija“ predlažu novi termin "intrategija“, za opisivanje učinka odluka uprave na predanost zaposlenika poduzeću.

Konkretnije, intrategija je proučavanje okoline poduzeća i unutarnjih procesa. Ona teži jačanju predanosti zaposlenika poduzeću, kao i njihova povjerenja u njegovu upravu. Svjesno ili nesvjesno, svaka odluka uprave ima stratešku posljedicu - povećanje ili smanjenje u dobiti - te intratešku posljedicu, odnosno jačanje ili slabljenje ljudske predanosti i povjerenja u poduzeće. Donošenje bilo koje odluke uzimajući u obzir samo jednu od ovih posljedica, jest, u najmanju ruku, nepotpuno, ako ne i prijetnja poslovanju i opstanku poduzeća.

S obzirom da kultura utječe na izvore i strukturu moći u poduzeću, samim time možemo reći kako ona utječe i na izbor i efikasnost metoda izvođenja promjena u poduzeću od strane onih koji posjeduju moć za provođenje istih. Bahtijarević-Šiber, (2008) ističe kako činjenica da kultura djeluje na sve komponente organizacije i poslovanja poduzeća rezultira time da ona ima značajan utjecaj i na konačne performanse poduzeća. Autori Denison (1990) i Mishra i Spreitzer (1998) proveli su višegodišnje istraživanje na uzorku od preko 39 poduzeća iz 20 industrijskih 
sektora kako bi istražili utjecaj organizacijske kulture na njihovu uspješnost i učinkovitost. Rezultati istraživanja ukazuju na prisutnost četiri obilježja kulture koja su povezana sa uspješnošću i učinkovitošću spomenutih poduzeća, a to su: uključenost zaposlenih, konzistentnost, prilagodljivost i misija poduzeća. Svojim su istraživanjem došli do zaključka kako svako od četiri pojedina obilježja organizacijske kulture pokazuje značajnu pozitivnu vezu s velikim brojem objektivnih i subjektivnih mjera uspješnosti i učinkovitosti navedenih poduzeća. Navedena četiri obilježja organizacijske kulture su ispitivana kroz dvije povezane studije. Prva studija je bila kvalitativnog karaktera i obuhvatila je pet poduzeća kako bi se identificirala obilježja kulture i priroda njihova odnosa sa uspješnošću poduzeća. U drugoj, kvantitativnoj studiji, provedeno je istraživanje koje se temeljilo na opažanjima vrhovnih menadžera o navedene četiri karakteristike organizacijske kulture i njihovom povezanošću sa subjektivnim i objektivnim performansama na uzorku od 764 poduzeća.

Dvije karakteristike organizacijske kulture; uključenost zaposlenih i prilagodljivost pokazatelji su fleksibilnosti, otvorenosti i spremnosti na promjene te su se pokazali kao jaki prediktori rasta poduzeća. Druge dvije karakteristike organizacijske kulture; konzistentnost i misija, iskristalizirali su se kao pokazatelji integracije, smjera i vizije, te su bili bolji prediktori profitabilnosti. Svaka od četiri karakteristike organizacijske kulture se pokazala kao značajan prediktor drugih kriterija uspješnosti kao što su kvaliteta, zadovoljstvo zaposlenika i ukupna uspješnost poduzeća. Rezultati su također pokazali kako su spomenute četiri karakteristike snažni prediktori subjektivnih kriterija uspješnosti, ali su ujedno bili i snažni prediktori objektivnih kriterija kao što su povrat na imovinu i rast prodaje, ali samo za velika poduzeća. Ovo istraživanje je potvrdilo da se kultura poduzeća može proučavati kao integralni dio procesa prilagodbe poduzeća i da specifične osobine kulture mogu biti korisni prediktori uspješnosti i učinkovitosti. U radu se također ilustrira kako se kvalitativna studija slučaja i induktivna teorija rasta mogu kombinirati s kvantitativnim usporedbama i teorijskim testiranjem kako bi se postigao napredak na specifičnim aspektima istraživanja organizacijske kulture.

\subsection{Povezanost koncepta učećeg poduzeća i performansi poduzeća}

Iako se broj znanstvenih studija iz područja organizacijskog učenja i učećeg poduzeća posljednjih godina dramatično povećao, još uvijek je nedostatan broj onih koji povezuju učinke učenja i koncepta usvajanja učećeg poduzeća u poduzeću sa njegovim performansama (Ellinger i sur., 2000; 2002). Jeong, Lee, Kim, Lee, Kim, (2007) su istraživali vezu između usvajanja koncepta učećeg poduzeća od strane pojedinca i uspješnosti poduzeća koju su mjerili pomoću dvije dimenzije; 
osjećaju pripadnosti poduzeću i zadovoljstvom posla koji se obavlja koristeći se pri tome skalom učenja kao mjerom za evidentiranje promjena. Jeong i suradnici su otkrili kako usvajanje koncepta učećeg poduzeća od strane pojedinaca u poduzeću doprinosi poboljšanju uspješnosti poduzeća javnih službi putem učenja i prilagodbe.

Za mjerenje koncepta učećeg pdouzeća korišten je mjerni instrument kojeg je osmislio i razvio Senge (1990) a koji se sastoji od dvadeset i tri faktora unutar pet čimbenika: sustavno razmišljanje, osobno usavršavanje, mentalni modeli, zajednička vizija i timsko učenje. Jeong i suradnici su došli do zaključka kako su svih pet dimenzija učećeg poduzeća imali pozitivan utjecaj na osjećaj pripadnosti i zadovoljstva poslom pojedinaca u poduzeću. Naravno, kao i svaka studija i ova ima svojih nedostataka. Kao prvo, u uzorak je uzeto samo devet poduzeća. Kao drugo, studija pretpostavlja da se uspješnost poduzeća može mjeriti pomoću samo dvije varijable; osjećaju pripadnosti poduzeću i osjećaju zadovoljstva poslom.

Drugi standardni instrument koji se obično koristi za mjerenje prisutnosti koncepta učećeg poduzeća unutar nekog poduzeća jest upitnik Dimension of The Learning Organization Questionnaire (eng. DLOQ) koji se sastoji od sedam dimenzija koje čine koncept učećeg poduzeća i u praksi je naišao na široku primjenu (Watkins i Marsick, 1997; Yang, Watkins i Marsick, 1998, 2004). Sedam dimenzija uključuje; kontinuirano učenje, znatiželju i dijalog, timsko učenje, izgrađene sustave, opunomoćivanje, povezivanje sustava s okolinom i strateško vodstvo.

Prema Ellinger i sur. (2002), četiri stotine srednje rangiranih menadžera jedne američke proizvodne tvrtke zatražile su ocjenu na Likertovoj skali sa šest stupnjeva intenziteta u upitniku koji je imao četrdeset i tri stavke vezane uz učeće poduzeće i dva skupa pitanja o perceptivnim mjerama uspješnosti, uključujući povrat ulaganja, prosječna produktivnost po zaposleniku, vrijeme potrebno za plasman novog proizvoda na tržište, vrijeme potrebno da tržište odgovori na plasirani proizvod, udio i trošak po transakciji i mjere financijske uspješnosti, uključujući povrat na kapital, povrat na imovinu i ostale. Rezultati su pokazali da je ukupno sedam dimenzija učećeg poduzeća imalo pozitivan utjecaj na financijske performanse poduzeća. Iako su rezultati istraživanja potvrdili rezultate prethodnih studija, ipak je potrebno ispitati utjecaj dimenzija učećeg poduzeća na jedan širi raspon financijskih i nefinancijskih pokazatelja rezultata poslovanja.

Učenje povećava šanse poduzeća da posluju uspješnije (Kim, 1993). Performanse poduzeća mogu biti povezane s financijskim ili nefinancijskim performansama. Tako primjerice, Mills i Friesen (1992) povezuju učenje s nefinancijskim performansama kao što su poticanje inovacija i unaprijeđenje odnosa s kupcima i dobavljačima, kao i sa implementacijom poslovnih strategija i profitabilnošću poduzeća kao jednom od ključnih mjera financijske uspješnosti. Autori Škerlavaj 
i Dimovski, (2007), Hernaus i sur., (2008) i Dermol (2012) koji su istraživali uspješnost poduzeća dovodeći u vezu organizacijsko učenje sa performansama poduzeća došli su do rezultata kako se financijske i nefinancijske performanse mogu dovesti u vezu sa kognitivnim promjenama i promjenama u ponašanju zaposlenih. Navedeni autori ističu kako samo kognitivne i bihevioralne promjene kao temeljni konstrukt organizacijskog učenja mogu dovesti do povećanja performansi. Rezultati empirijskog istraživanja jedne druge studije (Borovac Zekan, S., 2017) potvrdili su postojanje pozitivne veze imeđu razvijenosti koncepta učećeg poduzeća i performansi poduzeća. U navedenom istraživanju varijabla „performanse poduzeća“" sastojala se od financijskih performansi i performansi znanja pri čemu se pokazalo kako performanse znanja imaju veći značaj kod kreiranja varijable „performanse poduzeća“ od performansi znanja.

Tablica 2. prikazuje studije koje su dovele u vezu koncept učećeg poduzeća sa performansama, (financijske performanse, performanse znanja i neke druge performanse kao što je npr. ostvarenje misije poduzeća).

Tablica 2. Pregled studija o povezanosti koncepta učećeg poduzeća i performansi poduzeća

\begin{tabular}{|c|c|c|c|}
\hline Studija & $\begin{array}{c}\text { Financijske per- } \\
\text { formanse }\end{array}$ & Performanse znanja & Ostale mjere \\
\hline $\begin{array}{c}\text { Davis i Daley } \\
\quad(2008)\end{array}$ & $\begin{array}{l}\text { Svih sedam di- } \\
\text { menzija koleri- } \\
\text { raju sa FP; PL } \\
\text { najveća vrijednost } \\
(.599 * *)\end{array}$ & $\begin{array}{l}\text { Svih sedam dimenzija koleri- } \\
\text { raju sa KP, PL (najveća vrijed- } \\
\text { nost. } 542 * * \text { ) }\end{array}$ & $\begin{array}{l}\text { PCT prodaja novih } \\
\text { proizvoda kolerira } \\
\text { sa KP }\left(.199^{* *}\right)\end{array}$ \\
\hline $\begin{array}{l}\text { Ellinger, El- } \\
\text { linger, Yang } \\
\text { i Howton } \\
\text { (2002) }\end{array}$ & $\begin{array}{c}\text { Sve dimenzije } \\
\text { koleriraju sa FP, } \\
\text { utjecaj veličine od } \\
.246 \text { do } .312 \text { (LO } \\
\text { objašnjavaju } 25 \% \\
\text { varijance u ovim } \\
\text { mjerama) }\end{array}$ & $\begin{array}{l}\text { Sve dimenzijekoleriraju sa KP; } \\
\text { utjecaj veličine od.246 do. } 312 \\
\text { LO dimenzije objašnjavaju } \\
\text { 25\% varijance u ovim mjerama }\end{array}$ & $\begin{array}{c}\text { ROE,Tobinov } \\
\text { koeficijent, MVA, } \\
\text { Netto prihod/za- } \\
\text { poslenik=.104 do } \\
.108 \\
\text { Utjecaj veličine } \\
\text { Lo dimenzije } \\
\text { objašnjavaju 10\% } \\
\text { varijance u ovim } \\
\text { mjerama }\end{array}$ \\
\hline $\begin{array}{l}\text { Hernandez } \\
(2003)\end{array}$ & $\mathrm{N7A}$ & $\mathrm{CL}, \mathrm{ES}, \mathrm{EP}, \mathrm{SC}, \mathrm{PL}$ & Prijenos znanja \\
\hline $\begin{array}{l}\text { Kumar } \\
(2005)\end{array}$ & $\begin{array}{c}\mathrm{R} 2 \\
.336(\mathrm{CL} ; \mathrm{DI}) \\
.339(\mathrm{TL}) \\
.471 \\
(\mathrm{ES}, \mathrm{EP} ; \mathrm{SC}, \mathrm{PL}) \\
\end{array}$ & $\begin{array}{c}\mathrm{R}(2) \\
.180(\mathrm{CL}, \mathrm{DI}) \\
.284(\mathrm{TL}) \\
.371(\mathrm{ES}, \mathrm{EP}, \mathrm{SC}, \mathrm{PL})\end{array}$ & \\
\hline
\end{tabular}




\begin{tabular}{|c|c|c|c|}
\hline $\begin{array}{l}\text { Kumar i Idris } \\
\quad(2006)\end{array}$ & N/A & $\begin{array}{c}\text { ES, PL, TL imaju najsnažiju } \\
\text { vezu sa KP; ove tri varijable } \\
\text { objašnjavaju } 41 \% \text { varijance KP }\end{array}$ & \\
\hline $\begin{array}{l}\text { McHargue } \\
(2003)\end{array}$ & $\begin{array}{l}\text { FP-26\% varijance } \\
\text { (objašnjeno sa } \\
\text { omjerom duga, } \\
\text { volontiranjem i } \\
\text { sl.) } \\
\text { FP-53\% varijance } \\
\text { (TL, SC, PL) }\end{array}$ & $\begin{array}{c}\mathrm{KP}-26 \% \text { varijance objašnjeno } \\
\text { \# volontiranjem, netto imovi- } \\
\text { nom i SC, CL. }\end{array}$ & $\begin{array}{l}\text { Ostvarenje misije } \\
-16 \% \text { varijance } \\
\text { (objašnjeno volo- } \\
\text { ntiranjem, netto } \\
\text { imovinom, omje- } \\
\text { rom štednje, TL,CL }\end{array}$ \\
\hline $\begin{array}{l}\text { Rose,Salleh } \\
\text { i Kumar } \\
(2006)\end{array}$ & $\begin{array}{l}\text { FP-53\% vrijance } \\
\text { objašnjenosa TL, } \\
\text { PL i SC. }\end{array}$ & $\begin{array}{c}\mathrm{KP}-59 \% \text { varijance objašnjeno } \\
\text { pomoću Pl. ES, DI: }\end{array}$ & \\
\hline $\begin{array}{l}\text { Watkins, } \\
\text { Milton i Kurz } \\
\text { (2009) }\end{array}$ & $\begin{array}{l}\text { ES-korelira sa } \\
\quad \text { FP-.589 } \\
\text { EP-.625 sa FP } \\
\text { SC-.655 saFP } \\
\text { PL-.629 sa FP }\end{array}$ & $\begin{array}{c}\text { ES (.676) kolerira sa KP } \\
\text { EP }(.691-\mathrm{KP}) \\
\mathrm{SC}(.689-\mathrm{KP}) \\
\mathrm{Pl}(.660-\mathrm{KP})\end{array}$ & $\begin{array}{c}\text { ES kolerira sa .662 } \\
\text { ostvarenjem misije } \\
\text { SC (.631- MP) } \\
\text { Pl. ( } 613-\mathrm{MP})\end{array}$ \\
\hline $\begin{array}{l}\text { Wetherington } \\
\text { i Daniels } \\
\text { (2013) }\end{array}$ & $\begin{array}{l}\text { Sve dimenzije } \\
\text { koleriraju sa per- } \\
\text { formansama } \\
\text { (najveća korel- } \\
\text { acija sa PL) }\end{array}$ & $\begin{array}{l}\text { Sve dimenzije koleriraju sa } \\
\text { performansama poduzeća; PL } \\
\text { ima najsnažniji utjecaj }\end{array}$ & \\
\hline $\begin{array}{l}\text { Yang, Wat- } \\
\text { kins i Mar- } \\
\text { sick (2004) }\end{array}$ & $\begin{array}{l}\text { SEM, PL jedina } \\
\text { varijabla sa direk- } \\
\text { tinim utjecajem na } \\
\text { FP (.42) }\end{array}$ & $\begin{array}{l}\text { SC izravno utječe na KP (.35) } \\
\text { - ES indirektno utječe na FP } \\
\text { putem utjecaja ove varijable } \\
\text { na SC koja utječe na KP; KP } \\
\text { i FP koleriraju sa FP imajući } \\
\text { najsnažniji utjecaj naKP (.54 } \\
\text { vs .36) }\end{array}$ & \\
\hline \multicolumn{4}{|c|}{$\begin{array}{l}\text { Objašnjenje skraćenica: } \mathrm{FC}=\text { financijske performanse (engl. Financial perfomance ); } \mathrm{KP}=\text { per- } \\
\text { formanse znanja (engl. Knowledge performanse); } \mathrm{Cl}=\text { stvaranje stalnih prilika za učenje (engl. } \\
\text { Creates continuous learning opportunities); } \mathrm{DI}=\text { promicanje znatiželje i dijaloga (engl. Promote } \\
\text { dialoque and inquiry); } \mathrm{TL}=\text { poticanje timskog rada i timskog učenja (engl. Encourage collabora- } \\
\text { tion and team learning); } \mathrm{ES}=\text { uspostavljanje sustava za učenje i transfer znanja (engl. Establish } \\
\text { systems to share and capture learning); } \mathrm{EP}=\text { opunomoćivanje zaposlenika prema zajedničkoj viziji } \\
\text { (engl. Empower people towards a collective vision); } \mathrm{SC}=\text { povezanost poduzeća s okolinom (engl. } \\
\text { Make systemic connections between the organization and its environment) i } \mathrm{PL}=\text { vodstvo koje } \\
\text { potiče učenje(engl. Provide strategic leadership for learning) }\end{array}$} \\
\hline
\end{tabular}

Izvor: Watkins, K.E. (2017). Defining and Creating Organizational Knowledge Performance Educar, vol. 53/1, str. 211-226.

Velik je broj pokazatelja kojima je moguće mjeriti uspješnost poduzeća. Povrat na kapital (engl. Return On Equity - ROE) pokazuje kolika je dobit po kuni uloženog kapitala. ROE je i dobar pokazatelj brzine rasta poduzeća jer se smatra da ukupni prihodi ne mogu rasti po stopi većoj od trenutnog iznosa ROE, osim zaduživa${ }_{88}$ jem kod banaka. Povrat na imovinu (engl. Return On Assets - ROA) indikator 
je koliko je profitabilno poduzeće u odnosu na svoju ukupnu imovinu, a osim toga, daje i uvid u učinkovitost upravljanja imovinom poduzeća u svrhu ostvarivanja zarade. S druge strane, Škerlavaj i sur. (2007) upozoravaju kako pokazatelji uspješnosti poslovanja poduzeća ne mogu biti samo dobit, dodana vrijednost ili neka druga financijska mjera. Oni zastupaju stajalište prema kojem bi se trebalo uvažiti sve aktere poslovanja (zaposlenike, kupce, dobavljače....) prilikom izračuna uspješnosti poduzeća. Pa tako npr. Gorenak i Pagon (2006) smatraju dodanu vrijednost po zaposleniku središnjom objektivnom mjerom uspješnosti poduzeća povezanom s povećanjem tržišne vrijednosti i kvalitete proizvoda ili usluga.

\section{ZAKLJUČAK}

U ovom radu se teorijski povezuje organizacijsku kulturu sa performansama poduzeća. S obzirom da kultura utječe na izvore i strukturu moći u poduzeću, samim time može se zaključiti kako ona utječe i na izbor i efikasnost metoda provođenja promjena u poduzeću od strane onih koji posjeduju moć za njihovu realizaciju. Promjene, odnosno prilagodbu poduzeća njegovoj okolini je nemoguće uspješno ostvariti ukoliko poduzeće nema usvojen koncept učećeg poduzeća. Temeljne vrijednosti prilagodljive organizacijske kulture vezuju se uz sklonost prema promjenama, preuzimanju rizika, međusobnoj podršci zaposlenika, inovativnosti, kreativnosti i entuzijazmu. Može se primjetiti kako su navedene vrijednosti potpuno identične onima koje se nalaze i kod učećeg poduzeća. Prilagodljiva kultura tako ima eksterni fokus i tendenciju da konstantno teži fleksibilnosti. Samo prilagodljiva organizacijska kultura koja spremno prihvaća tržišne promjene, konstantno se prilagođavajući novim zahtjevima iz okoline, može stvoriti preduvjete za rast i razvoj poduzeća i u konačnici rezultirati ostvarenjem uspješnih performansi.

\section{LITERATURA}

1. Bahtijarević-Šiber, F. (2008). Organizacijska kultura, u: Sikavica, P., Bahtijarević-Šiber, F., Pološki Vokić, N., Temelji menadžmenta, Školska knjiga, Zagreb, str. 415.

2. Barney, J. B. (1986). Organizational culture: can it be a source of sustained competitive advantage?. Academy of management review, 11(3), str. 656-665.

3. Belak, S., Ušljebrka, I. (2014). Organizacijska kultura kao čimbenik uspješne provedbe organizacijske promjene. Oeconomica Jadertina, 4(2), str. 80-98.

4. Block, L. (2003). The leadership-culture connection: an exploratory investigation. Leadership and Organization Development Journal, 24, str. 318-334. 
5. Borovac Zekan, S. (2017). Učeće poduzeće kao model prilagodbe poduzeća kompleksnosti okoline, doktorska disertacija, Ekonomski fakultet, Split

6. Cardona, P., Rey, C. (2008). Management by missions. Basingstoke, England, Palgrave Macmillan.

7. Cooper, R. B. (1994). The inertial impact of culture on IT implementation. Information \& Management, 27(1), str. 17-31.

8. Ćuze, S., Načinović Braje, I. (2015). Uloga organizacijske kulture u provedbi organizacijskih promjena, Sveučilište u Zagrebu, Ekonomski fakultet, diplomski rad, rujan 2015.

9. Daft, R. L. (2004). Organization theory and design. Mason, Ohio: Thomson/ South-Western.

10. Denison, D. R. (1990). Corporate culture and organizational effectiveness. John Wiley \& Sons.

11. Denison, D. R., Mishra, A. K. (1995). Toward a theory of organizational culture and effectiveness. Organization science, 6(2), str. 204-223.

12. Dermol, V. (2013). Relationship between learning, knowledge creation and organisational performance. Annals of the Alexandru Ioan Cuza University-Economics, 60(1), str. 79-93.

13. Ellinger, A. D., Ellinger, A. E., Yang, B., Howton, S. W. (2002). The relationship between the learning organization concept and firms' financial performance: An empirical assessment. Human resource development quarterly, 13(1), str. 5-22.

14. Geus, A. (1997). The living company. Boston, Mass: Harvard Business School Press

15. Gorenak, I., Pagon, M. (2006). The Influence of Organizational Communication on Job Satisfaction of Police Officers. Organizacija, 39(4).

16. Hernaus, T., Škerlavaj, M., Dimovski, V. (2008). Relationship between Organisational Learning and Organisational Performance: The Case of Croatia // Transformations in business \& economics, 7 (2008), 2; str. 32-48.

17. Jeong, S. H., Lee, T., Kim, I. S., Lee, M. H., Kim, M. J. (2007). The effect of nurses' use of the principles of learning organization on organizational effectiveness. Journal of advanced nursing, 58(1), str. 53-62.

18. Kavanagh, M. H., Ashkanasy, N. M. (2006). The impact of leadership and change management strategy on organizational culture and individual acceptance of change during a merger. British Journal of Management, 17(S1), str. 81-103.

19. Kim, D. H. (1993). A framework and methodology for linking individual and organizational learning: Applications in TQM and product development (Doctoral dissertation, Massachusetts Institute of Technology). 
20. Martinsons, M. G., Chong, P. K. (1999). The influence of human factors and specialist involvement on information systems success. Human relations, 52(1), str. 123-152.

21. Mills, D. Q., Friesen, B. (1992). The learning organization. European Management Journal, 10(2), str.146-156.

22. Mishra, A. K., G. M. Spreitzer (1998). Explaining how survivors respond to downsizing: The roles of trust, empowerment, justice, and work redesign. Academy of Management Review, 23: str.567-588.

23. Needle, D. (2010). Business in context: An introduction to business and its environment. Cengage Learning EMEA.

24. Prosser, J. (ed.) (1999). School Culture. London: P.C.P.

25. Ravasi, D., Schultz, M. (2006). Responding to organizational identity threats: Exploring the role of organizational culture. Academy of management journal, 49(3), str. 433-458.

26. Schein, E. H. (1985): Organisational culture and leadership: A dynamic view. San Francisco.

27. Schein, E. H. (1996). Three cultures of management: The key to organizational learning. Sloan management review, 38(1), 9.

28. Schein, E. H. (2010). Organizational culture and leadership (Vol. 2). John Wiley \& Sons.

29. Senge, P. (1990). The fifth discipline: The art and science of the learning organization. New York: Currency Doubleday.

30. Škerlavaj, M., Štemberger, M. I., Dimovski, V. (2007). Organizational learning culture - the missing link between business process change and organizational performance. International journal of production economics, 106(2), str. 346-367.

31. Vrdoljak Raguž, I., Borovac Zekan, S. (2017). Organizational culture and leadership style: key factors in the organizational adaptation process //Ekonomski vjesnik : časopis Ekonomskog fakulteta u Osijeku, 30 (2017), 1; str. 209-219.

32. Watkins, K. E. (2017). Defining and Creating Organizational Knowledge Performance. Educar, vol. 53/1, str. 211-226.

33. Watkins, K. E., Marsick, V. J. (1997). Dimensions of the learning organization questionnaire. Warwick, RI: Partners for the Learning Organization

34. Whiteley, A., Price, C., Palmer, R. (2013). Corporate culture change: adaptive culture structuration and negotiated practice. Journal of Workplace Learning, 25(7), str. 476-498. 
35. Yang, B., Watkins, K. E., Marsick, V. J. (2004). The construct of the learning organization: Dimensions, measurement, and validation. Human resource development quarterly, 15(1), str. 31-55.

36. Žugaj, M., Schatten, M. (2005). Arhitektura suvremenih organizacija. Tonimir.

37. Žugaj, M., Bojanić-Glavica, B. (2004). Teorijske odrednice organizacijske kulture Varaždin: TIVA. 


\title{
Senka Borovac Zekan
}

University Department of Professional Studies, University of Split, Split, Croatia sborovac@oss.unist.hr

\section{CONNECTION OF ORGANIZATIONAL CULTURE AS A KEY FACTOR OF BUILDING THE LEARNING COMPANIES AND THE PERFORMANCE OF ENTERPRISES}

Received: June 27, 2018

Accepted: August 28, 2018

Review

\begin{abstract}
Obviously, today there is a even more need for companies to continue to work on their excellence through the adjustment process. In achieving this goal it is necessary to initiate all the knowledge resources in the enterprise. Permanent competitive advantages are achieved exclusively through knowledge. This claim is especially true in cases where a knowledge of an enterprise is difficult or even possible to copy. This is particularly true of organizational culture that encourages cooperation and exchange of knowledge. Enterprise's ability to learn and its ability to use relevant knowledge in its business and the mentioned not to be forgotten, has great significance in the knowledge-based business age. Knowledge and learning thus become rare and valuable sources of competitive advantage, and among other things, for these reasons, it has become extremely difficult today to find a manager who at least declaratively ignores the importance of organizational climate and the construction of a learning enterprise. In order for a company to be successfully transformed into a learning enterprise, as a first step it should identify in that process the level of culture it belongs to, and then identify the weak points that need to be changed. The transformation of companies whose internal culture is "negative" or as some authors still call it "pathological" or "bureaucratic" should change into a company with positive-generative internal organizational culture. All mentioned should ultimately have a positive impact on organizational performance.
\end{abstract}

Keywords: organizational culture, enterprise learning, business adaptation, performance

JEL: M14 